\title{
A Systematic Review of Internet Communication Technology Use by Youth in Foster Care
}

\author{
Melanie Sage $^{1}$ (D) $\cdot$ Sebrena Jackson ${ }^{2}$ (D)
}

Accepted: 8 January 2021 / Published online: 2 February 2021

(c) This is a U.S. government work and not under copyright protection in the U.S.; foreign copyright protection may apply 2021

\begin{abstract}
This systematic narrative review of the literature reports on the experiences of foster youth regarding the use of Internet Communication Technologies (ICTs) such as social media, focusing only on studies that include youth voice. We searched seven databases for articles published internationally from 2010 to 2020 in which foster youth were interviewed regarding their beliefs about ICTs. Youth report benefits of ICTs including to their relationships and identity formation opportunities, and discuss risks of ICTs and how they manage them. ICTs may benefit positive youth development. Stakeholders may consider ways to assess and support healthy ICT use.
\end{abstract}

Keywords ICT $\cdot$ Foster care $\cdot$ Child welfare $\cdot$ Technology $\cdot$ Social media

In 2019, in the United States, about 160,000 youth between the ages of 11-20 were in foster care (Children's Bureau, 2020). Older youth in foster care experience frequent living transitions and relational losses (Fawley-King, Trask, Zhang, \& Aarons, 2017; Mitchell, 2018). Relationship maintenance promotes positive outcomes for foster youth, especially as they leave foster care (Blakeslee \& Best, 2019; Graham, Schellinger, \& Vaughn, 2015; Munson, Smalling, Spencer, Scott, \& Tracy, 2010; Pryce, Napolitano, \& Samuels, 2017; Seita, Day, Carrellas, \& Pugh, 2016). Information and Communication Technologies (ICTs) provide one way for youth to stay connected to others as they move through the child welfare system. ICTs are digital tools and applications that allow communication with others, such as smartphones, texting, and social media. They are constantly used by the general population of youth in the United States to stay connected to people they care about (Anderson \& Jiang, 2018; Christensson, 2010). The Pew Internet Center found that $95 \%$ of teens now have smartphones or access to one (Anderson \& Jiang, 2018). Yet, foster parents, group home staff, and child welfare administrators see foster youth at

Melanie Sage

msage@buffalo.edu

1 School of Social Work, University at Buffalo SUNY, Buffalo, NY, USA

2 School of Social Work, University of Alabama, Tuscaloosa, Alabama, USA high risk of harm related to the use of these technologies, and therefore restrict their use (Badillo-Urquiola, Page, \& Wisniewski, 2019; Forenza, Bermea, \& Rogers, 2018; Stott, MacEachron, \& Gustavsson, 2016).

Beyond staying connected to friends, Pew found that teens use technology for self-expression, to meet others with shared interests, for entertainment, and to find information (Anderson \& Jingjing, 2018). Child welfare systems are often risk-averse and may prioritize youth safety over opportunity when it comes to helping youth maintain relationships via ICTs (Simpson, 2016). This aversion to risk may further leave foster youth at a relational disadvantage related to access via ICTs.

There is no explicit federal policy or common practice that specifically addresses the use of ICTs by foster youth. However, several laws point toward a more permissive view of ICT use than is indicated by existing research regarding actual access. For instance, the Strengthening Families Act (2014) requires that child welfare systems assure foster youth have typical age-appropriate experiences and that foster parents provide a "reasonable and prudent parent standard" related to youth participation in activities. The Family First Legislation, enacted in 2019, provides additional focus on making sure older youth leave foster care with employment and relationship skills (Lindell, Sorenson, \& Mangold, 2020). Further, during the COVID-19 pandemic of 2020, many youth in foster care lost normal face-to-face contacts with people they cared about. Their lack of access 
to technology led ACF Children's Bureau Associate Commissioner, Jerry Milner, to issue a letter to states encouraging them to utilize funds to purchase cell phones and other technology for older foster youth so that they could sustain important contacts (Milner, 2020). Thus, there is no federal restriction that disallows the use of ICTs by youth in foster care, and federal guidance counters the fear-based restrictiveness caregivers and other system stakeholders may employ.

The objective of this systematic narrative literature review is to provide a scan of available research about the use of ICTs by foster youth, especially as it pertains to how it might impact their important relationships. This systematic literature review emphasizes youth voice, i.e., what youth have to say about their use of ICTs, and positive youth development, to inform future research, policy, and practice.

\section{Youth Voice and Positive Youth Development}

Foster youth typically experience a lack of choice in decisions about their lives (Armstrong-Heimsoth et al., 2020; Beal et al., 2019). Youth in care often experience rule-making as inconsistent, arbitrary, and not individualized (Rauktis, 2016). Restrictiveness is typically due to adults' concerns about the youth's capacity for good decision-making (Havlicek, 2011; Olson, Scherer, \& Cohen, 2017). However, the lack of choice further limits their practice of healthy decision making. Youth voice is a term used to signify the ways that youth are allowed to have say in the decisions that affect them, and acknowledges that youth should be able to speak about their view of what is in their best interest (Nybel, 2013). Here we use the term youth voice to center what youth have to say about their ICT use.

Positive Youth Development (PYD) is an approach to youth programming that focuses on healthy development by enhancing youths' strengths and supportive contexts (Lerner et al., 2015). Instead of using a problem-focused frame, it recognizes assets, competencies, and supports that promote well-being and positive outcomes (Eichas, Ferrer-Wreder, $\&$ Olsson, 2019). PYD interventions promote interpersonal skills while reducing risks (Taylor, Oberle, Durlak, \& Weissberg, 2017). PYD emphasizes capacities, focusing upon five "Cs": competence, caring, connection, character, and confidence. While literature about foster youth using ICTs is generally risk-focused, a PYD approach offers an opportunity to consider that youth already employ capacities in the "five Cs" to navigate difficult online situations. It also provides a framework for how ICTs may encourage the deployment of these capacities to strengthen their resilience and decisionmaking skills while giving specific attention to the needs and capacities of youth to develop caring connections.

\section{Relationships for Foster Youth}

Foster youth in the child welfare system frequently experience a relational deficit, restricted from normal maintenance of connection with parents, relatives, and friends (Storer et al., 2014). The lack of relational capacities prevent some foster youth from developing the protective factors provided by relationships and secure connections (Denby, Gomez, \& Alford, 2016). Given violations of trust experienced by many youth within their families, foster youth sometimes need significant help in learning how to cultivate and maintain healthy relationships and support networks (Goodkind, Schelbe, \& Shook, 2011). Lack of relational safety and healthy modeling may put youth at higher risk when navigating online relationships. Still, access to ICTs may also provide a resource for strengthening relationships and related capacities.

Much of the existing research on healthy relationships for youth in care focuses on the value of relationships with adult mentors. It demonstrates that permanent relationships with positive adults are an influential protective factor against adverse outcomes, providing critical support to youth as they transition to adulthood. According to Salazar, Keller, \& Courtney (2011), relational permanency comes in many forms and often includes informal arrangements with relatives or other caring adults. Foster Club, a national network for youth in foster care, suggests that youth form "permanency pacts" with supportive adults who provide specific supports for them beyond the transition from foster care (Foster Club, 2016). Youth need multiple domains of relational support to provide life-long, kin-like relationships in order to have successful outcomes (Best \& Blakeslee, 2020; Blakeslee, 2015). In addition to mentors and other more formal relational supports, youth draw upon the support of peers, significant others, and birth families (Best \& Blakeslee, 2020).

In their longitudinal youth-centered research study, Mitchell, Jones, \& Renema (2015) found that nearly 50\% of youth reported a goal related to forming or building relationships (i.e., building a family and reconnecting with family). Data from the National Survey of Child and Adolescent Wellbeing indicates that peer-based relationships play important roles for foster youth in internalizing, externalizing, and behavioral outcomes (Thompson et al., 2016). However, little research has investigated the value of peer-based and same-aged social support for foster youth. No research that we were able to identify focuses on ways foster youth maintain healthy technology-mediated peer-based and supportive relationships. In sum, we know youth benefit significantly from supportive relationships with adults, and likely with peers and their biological 
families. Still, a research gap exists related to the ways ICTs might support these relationships.

\section{ICT Use by Foster Youth}

Because of the paucity of research synthesis about the experiences of ICT use by foster youth, especially from the perspective of youth themselves, we focus on addressing this gap. Foster youth may indeed be at heightened risk when using ICTs, given their histories and experiences of victimization and other personal and interpersonal risk factors (Espinoza \& Wright, 2018; Leung, 2014). It is true that some youth experience risks when using ICTs. Resilience, or the ability to overcome adversity, is strengthened through the practice of navigating risky situations successfully (Fergus \& Zimmerman, 2005; Hinduja \& Patchin, 2017). From a Positive Youth Development perspective (Taussig et al., 2019) and a social justice and human rights perspective (Lundy, 2011; McLaughlin, Gray, \& Wilson, 2015), it is important that youth have access to the resources that help them connect to the people who are important to them, and that caregivers do not withold these opportunities because of the potential of risk. Much like when youth are learning to drive a car, the role of the reasonable and prudent parent (Simmons-Horton, 2017) is to supervise, train, correct, allow for mistakes, draw on strengths, and build youth competence and confidence.

\section{Present Study}

This study fills a gap in the sparse research that exists about the experiences of foster youth who use ICTs, especially research that involves youth or their first-hand accounts. There are no systematic literature reviews on the use of ICTs by foster youth that center their perspectives to the best of our knowledge. We aim to specifically address the gap of knowledge about what foster youth and former foster youth say about how they are impacted by ICT use, focusing on the impact of ICTs on relationships, which are critical to youth as they age out of foster care. Assumptions that influence our analysis are that (1) foster youth voice is often absent in decision-making about their lives, to the detriment of skills needed for independence, and (2) inadequate attention is given to the use of ICTs, especially beneficial uses, for adolescents in foster care.

This systematic narrative review of literature focuses on peer-reviewed research published between January 2010 to 2020 . Our aim is to (1) describe how foster youth discuss the risks and benefits of their use of ICTs, and (2) report the relational outcomes of ICT use, as defined by foster youth and former foster youth. We then use a PYD framework to assess the match between the findings of our search to PYD constructs. The review aims to bring together trustworthy evidence from the literature to help researchers, policymakers, practitioners, foster parents, and other stakeholders understand foster youth perspectives about their ICT use to improve inclusion of youth voice in decision making. We also aim to inform relationship intervention research and practice by identifying themes and gaps related to ICT use.

\section{Method}

This systematic review used the Preferred Reporting Items for Systematic Reviews and Meta-Analyses (PRISMA) methodology (Moher, Liberati, Tetzlaff, \& Altman, 2009) and flow diagram to systematically evaluate articles related to perceptions of ICT use by foster youth, inclusive of peerreviewed research articles and dissertations.

\section{Literature Search and Data Collection}

\section{Literature Search}

The search occurred in January 2020, for articles published from January 2010 to January 2020 and included seven databases. Databases included Academic Search Ultimate, OpenDissertations, PsycARTICLES, Psychology and Behavioral Sciences Collection, PsycINFO, Social Work Abstracts, SocINDEX, limited to full-text articles available at the university of the first author, published in English. Search terms were full abstract searches for Cyber* OR internet OR "social media" OR "digital" OR "online" OR online OR techno* OR "social network*" AND foster youth or foster child* or foster care or child welfare or "looked after."

\section{Inclusion and Exclusion Criteria}

We screened articles for the inclusion of first-hand accounts of foster youth or former foster youth of any age. We defined ICT use as any article that discussed the use of the internet, smartphones, or social media that allow internet-mediated communication with others. Articles were excluded that were not written in English, were published before 2010 or after January 2020, and that did not include youth voice as a direct source of research data. Articles that focused on the assessment of adult voice or expert opinion were excluded, as were articles that were not peer-reviewed. In cases where 

D, Liberati A, Tetzlaff J, Altman DG, The PRISMA Group (2009). Preferred Reporting Items for Systematic Reviews and Meta-Analyses: The PRISMA Statement. PLoS Med 6(7): e1000097. https:// doi.org/10.1371/journal.pmed 1 000097For more information, visit www.prisma-statement.org
Fig. 1 Adapted from Moher

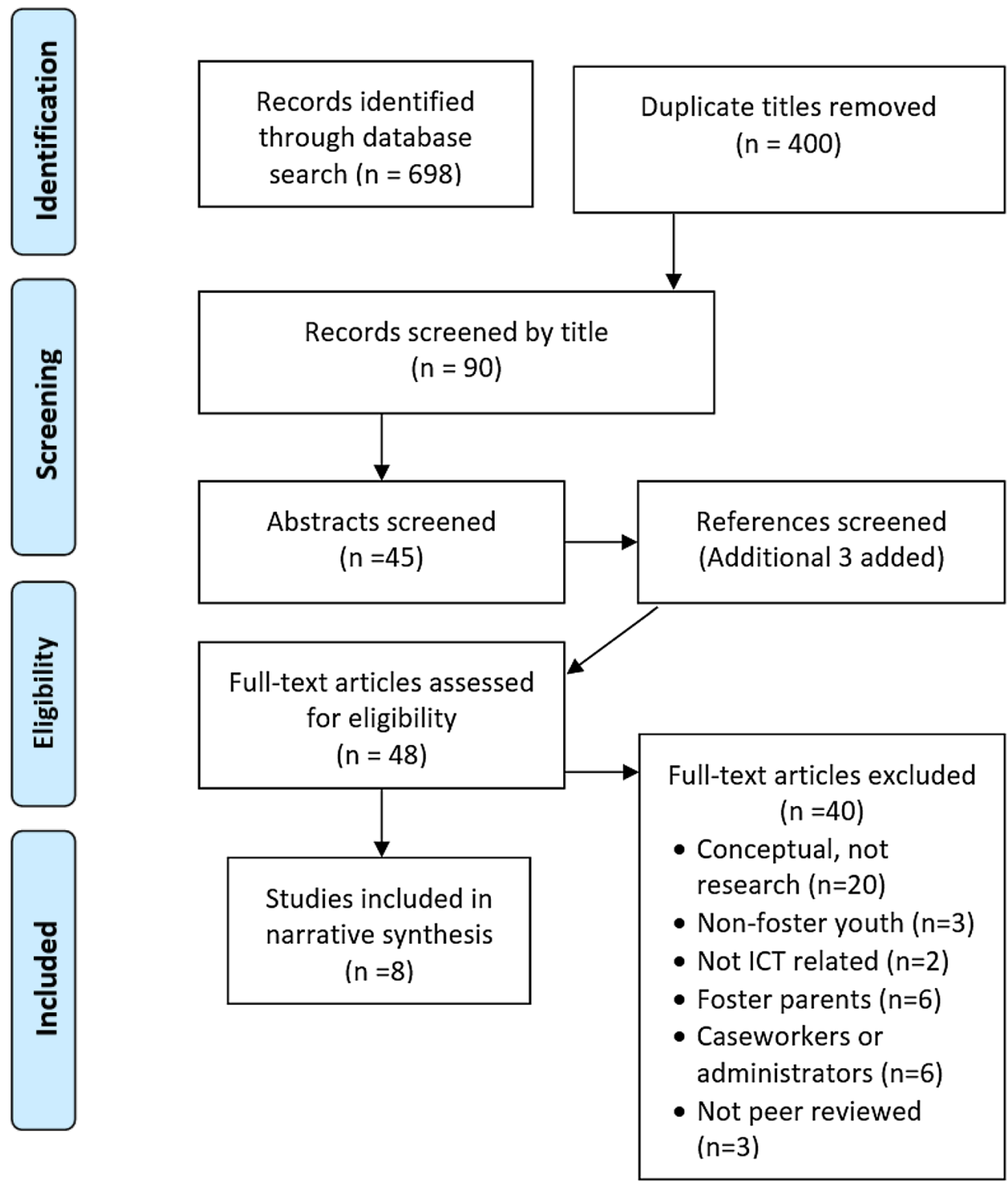

articles reported on youth and caregiver data together, we included only the data and related findings about youth voice in the analysis.

\section{Data Collection}

The search and data collection procedure is listed in Fig. 1, PRISMA Diagram Flow. The search of seven databases resulted in 698 articles and 400 articles once duplicates were removed. Titles were scanned for relevance, resulting in 90 articles. Next, we scanned abstracts of articles for inclusion criteria, resulting in 45 articles. The references of these articles were reviewed, resulting in the inclusion of three more articles. Both authors reviewed the full text of 48 articles, using a consensus method for final inclusion. This resulted in eight articles that presented original research and included the experiences of foster youth. The most common reasons that articles were excluded were because they were conceptual articles $(n=20)$ or sourced data from administrators, professionals, or foster parents $(n=12)$ rather than foster youth. Once the final articles were identified, they were entered into a spreadsheet in Google Sheets for charting and data extraction by both authors (Fig. 1).

We used a data extraction form to collect (1) country of study; (2) methodology of article; (3) types of technology discussed in articles; (4) demographics of subjects; (5) whether the lens focused primarily on risks, benefits, or both; (6) youths' uses of ICT use; (7) youths' perceptions of benefits of ICT use; (8) youths' perceptions of risks; (9) youths' strategies for navigating risks.

Because articles used primarily descriptive and qualitative data, it was impossible to conduct analysis related to the findings' statistical significance. Therefore we used a 
Table 1 Description and summary of included studies

Author (Year) Location and Participants

Denby et al. 2016

USA, Foster youth $(n=16)$

Fowles (2018)

USA, Foster care alumni attending college $(n=6)$

Key findings

- Phone helped youths establish and strengthen relationships

- Youth participants felt that the smartphone gave the a voice and choice in the people with whom they wanted to converse

- Challenges related to conflict with foster parents around smartphone access emerged as a prominent theme in focus groups

- Primarily use social media to curate information for their own benefit

- Social media connections were a direct reflection of resources and access points they had in previously-formed personal relationships

- The positive youth development (PYD) lens provided insight into participants' resources and needs, most notably, needs of connection, confidence, and competence

Hammond, Cooper, \& Jordan (2018) UK (England), Foster youth $(\mathrm{n}=10)$ and social care professionals $(n=35)$

- The contacts as currency theme focused on the notion that connecting and socializing with contacts beyond the local residential care context was protective

- The promoting and protecting the self theme highlighted how adolescents are navigating the psychosocial concerns of experiencing a perceived smaller social network, how they experienced contact with family members, negotiated joining or not joining networks occupied by professionals and the challenges of representing a coherent and cohesive online persona

- Findings from the third theme, transitions, highlighted adolescents' ability to stay connected to the professional staff who offered a social capital reserve. Social media had roles before, during, and after transitions experienced from a residential social care related to supporting youth relationships

Rueda, Brown, \& Geiger (2019)

USA, Program staff $(n=12)$ and foster youth $(n=13)$

Roche, Vateriaus, \& Young (2015) USA, Foster care alumni $(n=1)$
- Technology was a central component of adolescents' romantic and sexual relationships

- Teens became involved in one another's dating lives via technology

- Potential risks were discussed of utilizing technology in dating contexts

- Participant's technology experiences while in foster care were limited and colored her future use and perceptions of technology

- Participant reported finding value in reconnecting with her biological family and her foster siblings on Facebook

- Using the multicultural feminist approach provided emerging evidence that a foster care alumana's experience with technology was different in terms of access, purpose, and use than the majority of Millennials 
Table 1 (continued)

\begin{tabular}{|c|c|c|}
\hline Author (Year) & Location and Participants & Key findings \\
\hline Sen (2016) & $\begin{array}{l}\text { UK (Scotland), Foster care alumni }(n=6) \text { and } \\
\text { foster youth }(n=4)\end{array}$ & $\begin{array}{l}\text { - A majority of participants received some form of } \\
\text { online verbal abuse from other young people they } \\
\text { knew, but these experiences were not markedly } \\
\text { more negative than peer experiences in other } \\
\text { research } \\
\text { - Participants' use of digital media revolved around } \\
\text { a narrow range of activities-primarily communi- } \\
\text { cation via social networking sites and texting to } \\
\text { people they already knew offline } \\
\text { - Foster care alumni and care leavers experienced } \\
\text { greater barriers to accessing the newest technology } \\
\text { and greater difficulty getting online }\end{array}$ \\
\hline Williams-Peters (2014) & $\begin{array}{l}\text { Republic of Trinidad \& Tobago, Foster youth } \\
(\mathrm{n}=24)\end{array}$ & $\begin{array}{l}\text { - The opportunity to engage in new relationships, } \\
\text { albeit digitally, appeared to be a strong motivator } \\
\text { for ICT use among youth } \\
\text { - There was an increased role in surveillance of } \\
\text { children's activities by staff who took a more } \\
\text { protective and paternalistic stance } \\
\text { - Staff acknowledged the competence of children } \\
\text { in using ICTs and showed willingness to learn } \\
\text { from children, although with some suspicion and } \\
\text { concern }\end{array}$ \\
\hline Wilson (2016) & UK (Scotland), Foster youth $(n=22)$ & $\begin{array}{l}\text { - The portability of ICTs helped youth cope with } \\
\text { frequent moves } \\
\text { - ICTs were important for maintaining pre-existing } \\
\text { relationships with others } \\
\text { - ICTs considered technologies of self-care: helping } \\
\text { participants deal with anxiety and stress }\end{array}$ \\
\hline
\end{tabular}

narrative synthesis of cross-cutting themes focused on the research questions (Baumeister \& Leary, 1997) using thematic analysis as an approach (Braun \& Clarke, 2014; Smith, 2015) (Table 1).

\section{Results}

\section{Summary of Included Articles}

All eight studies were original research approved by relevant institutional or oversight boards. We classified them according to the Hierarchy of Evidence (Murad, Asi, Alsawas, \& Alahdab, 2016), and original research was further classified by methodology. Because we screened out expert opinion, articles were only eligible for levels 2-5 (observational descriptive, analytical, quasi-experimental; cohort; randomized control; systematic reviews; and meta-analyses). All of the articles were observational cross-sectional descriptive studies. Methodologies of included studies included qualitative interviews (Fowles, 2018; Rueda et al., 2019; Sen, 2016), single case study design (Roche et al., 2015), survey research (Denby et al., 2016); focus groups (Denby et al., 2016; Rueda et al., 2019), and extended ethnographic observations (Williams-Peters, 2014; Wilson, 2016). One dissertation was included (Fowles, 2018), and all other papers appeared in peer-reviewed journals.

All eight articles were classified by country, given that policy and practice for youth in care are impacted by legal structures and social attitudes that are geographically bound (Benbenishty et al., 2015). Articles were coded by the country of the first author in all cases. Four articles originated in the United States. Three articles originated in the United Kingdom, including the countries Scotland $(n=2)$ and England $(n=1)$, and one article originated in Trinidad.

The samples varied in size from a single-person case study of a former foster youth to the largest study in Trinidad, which included 22 youth who lived in two residential treatment homes. The setting of most studies was either residential treatment or foster care homes. Youth in the studies ranged from 13 to 30, and some included adult youth reflecting on their experiences in care. Some studies offered direct quotes from youth, whereas others summarized themes from conversations with youth.

\section{Themes}

To answer our first question, how youth describe the benefits and risks of ICT use, we categorized findings into thematic groupings agreed upon by both authors. Themes 
below include quotes or summaries of salient themes in the research. Summarily, youth described that the benefits of ICT use, including (a) access to information and resources; (b) the ways that social media helped them maintain connections; (c) that ICTs allowed them to build social capital; (d) normalcy; (e) a tool for relaxation or recreation; (f) empowered voice and independence; and (g) identity formation and relaxation.

Additionally, youth described their perceptions of risks of ICTs, including (a) internet-mediated sexual exploitation and dating violence; (b) cyberbullying and harassment; (c) the difficulty of navigating complex relationships online; (d) the distraction caused by ICTs; (e) the risk of being monitored by agency staff through the use of ICTs. Youth also reported ways that they navigated these risks. They used a number of strategies, including (a) using technology settings to control the privacy and who has access to their personal information, and limiting social media friendships to people who they know; and (b) seeking help from adults.

Finally, youth discussed the ways that ICTs supported relational connections in their lives. They said ICTs helped them with, (a) finding and maintaining relationships with biological family members; (b) making and sustaining friendships and romances; (c) supporting their offline relationships; and (d) improving relationships with formal supports.

The themes above are elucidated in the following sections. When applicable, the words of current and former youth themselves are extracted from the relevant studies. However, in some of the studies, such as ethnographies, the themes are summarized and are already categorized by the study authors. In these cases, content from the researcher's themes are extracted to fit the categories identified in this study.

\section{Information and Resources}

Prevalent in a study of college-age youth (Fowles, 2018), the ability to connect to information on social media groups helped youth keep up with campus events, so they knew about opportunities. One participant in this study reported, "sometimes, I find out a lot of the information like events or volunteer opportunities or resources and scholarships on Facebook (p. 47)." This information-finding using ICTs lasts into adult life, as exemplified in Roche et al. (2015), "they'll post recipes and stuff for a variety of different foods. It is one more note card I don't have to have in my recipe box. It expands my knowledge on available meals I can cook. I love that stuff" (p. 5). Adult former foster youth, in particular, reported their social media use as mostly instrumental rather than social (Fowles, 2018; Roche et al., 2015).

\section{Maintaining Connections}

Many youths reported that ICTs kept them connected to friends they met while in care. For instance, "Almost all of my friends on Facebook are actually former foster youth or former probation youth, and I know them from organizations, from my time at these organizations," (Fowles, 2018, p. 50); "I joined Facebook in 2010 so only 3 years that I've had it. But I think it's fascinating because it allows you to connect to people from your past that you haven't spoken to in almost 10 years and they find you on Facebook. It's like oh my gosh! You know. It's a way of reestablishing those ties..." (Roche et al., 2015, p. 5).

\section{Building Social Capital}

Across studies, youth mention how ICTs allow them to connect in ways that build their social capital, i.e., their position in relation to others that might work to their advantage later. Hammond et al. (2018) describe, for instance, a young male aging out of care who discussed how he could call upon his online friends if he needed a place to sleep. Youth in the same study described connecting to youth in previous placements to maintain a network in times of need. Young people also considered ways to build relational capital with professors and others through self-presentation via Facebook groups to demonstrate their commitment to school activities. "If I like or share something, it gives professors a glimpse of my character and the things I value (p. 50)" Youth across studies talked about their networks, including loose ties, providing critical information. For instance, "I definitely think that, when you have the right friends on Facebook and the organizations, and if you put out there 'looking for housing,' I feel like they would get a response. I would say you need to have those people there first, somebody that can direct you to the right place, and, sometimes, you don't know who that is" (Fowles, 2018, p. 60).

\section{Normalcy}

The theme of normalcy came up across articles related to technology access in their same-age peer groups. Wilson (2016) noted that having a smartphone symbolized not only a normal youth experience for participants, but also dignity and status. Additionally, it provided a sense of belonging. For instance, a former foster youth in college said, "a lot of times, when I share stuff or post things, it's definitely about being thankful that I've found a community" (Fowles, 2018, p. 50). Denby (2016) also reported on the ways technology afforded typical experiences to youth in care, in that they were able to manage visitations and take on typical youth responsibilities. Williams-Peters (2014) framed this as exposure to the "outside world" (p. 178), which kept young 
people connected to youth culture through access to entertainment websites.

\section{For Recreation, Relaxation, Self-soothing}

One full article explicitly focused on the ways youth with foster care experiences used ICTs for self-care (Wilson, 2016). For instance, the author describes that youth used their phones as portable photo albums and address books, and plated soothing music and as a way to manage stress. Williams-Peters (2014) also noted that youth posted music on YouTube, took digital pictures, and used internet gaming as a form of fun, belonging, and entertainment.

\section{Empowered Voice and Independence}

Denby et al. (2016) pointed out that youth felt empowered by the use of smartphones, as they were able to contact their caseworker and other important people directly, and could make decisions such as canceling visits. Similarly, WilliamsPeters (2014) noted that the youth developed teaching roles in helping staff in their group home with technology, reversing the usual roles of expert. They also were able to use technology subversively because they knew more than the care workers; for instance, youth shared files with each other and posted videos online when they were not meant to. This subversion offered them agency to choose their own online representations, aiding in self-determination, despite their normally over-regulated environments. The power of unregulated contact came up in other articles; "online platforms afford youth opportunities to practice identity formation and intimacy in less governed spaces with increased opportunity to interact with peers and real or potential romantic or sexual partners" (Rueda et al., 2019, p. 4). In a residential home, caseworkers restricted young women from technology as a punishment related to their behavior. Still, they would exercise agency by bypassing the rules and having friends make calls for them, "you better call this person and tell them this, this, and this, okay" (p. 15).

\section{Identity Formation and Exploration}

Youth across studies discussed opportunities to consider and frame their identities based on their terms, especially identities outside their roles as foster youth. They formed identities not only regarding performative representations but also internalized representations. For instance, Wilson (2016) discussed how technology symbolized a sense of belonging in contemporary culture for one youth, "having her phone with her, feeling it in her pocket, gave her a sense of security and confidence. She also liked to listen to recordings of birdsong and to the sound of cars passing in the rain through her phone" (p. 290). Youth also talked about crafting identities that allowed them to escape their roles in care; former foster youth participants in the Fowles (2018) study frequently reported keeping their social media postings professional, networks small, and not talking about their histories of child welfare system involvement. Although some were in Facebook groups for former foster youth in college, they noted the groups were secret so nobody could find them. Williams-Peters (2014) also discussed how youth made choices regarding sharing their care status on social media platforms.

\section{Risks}

\section{Sexual Exploitation and Dating Violence}

Sen (2016) reported that one participant described a negative experience that she did not want to talk about, in which she met up with someone who was actually "somebody else" (p. 1070). In the Rueda et al. (2019) study of pregnant and parenting girls in residential treatment, quantitative surveys of the 59 young women indicated that $60 \%$ had experienced online dating violence, and $58 \%$ reported that they had perpetrated it. In the same sample, however, it is worth noting that in-person dating perpetration and victimization rates were significantly higher, suggesting that this technologymediated violence existed before or alongside the technology-mediated dating violence. Participants in this study also experienced sexual advances online related to assumptions about their status of pregnancy or motherhood, for instance, “There's guys that'll be like, 'Oh, you're pregnant... they say the pregnant ones are more crazy in bed (Lettie)" (p. 12).

\section{Bullying and Harassment}

In multiple studies, youth described people bothering them online. Sen (2016) said five of his six subjects reported that they either had first-hand experiences or knew about someone in their community of friends who experienced online bullying. For instance, "they say stuff that's not true about them and they make some rumour up about them and make web pages up about them (p. 1070)."

\section{Navigating Complex Relationships}

Youth across studies discussed multiple kinds of complex online relationships related to their care status. For instance, in Rueda et al. (2019), a youth describes her relationship with the father of her baby, "whenever I send him a picture of [daughter], he puts a sad face, wishing he was there... I say, "one day you will, but you have to fix your problems first" (p. 13). In several instances, navigation of complex relationships included painful emotional rejections that were technology-mediated; for example, "if I would tag him on 
something on Facebook with her [daughter's] picture, he would hide it from his timeline. 'Oh, I don't have a daughter"” (Rueda et al., 2019, p. 14).

In some instances, the complicated relationship caused by ICT use was between the youth and residential staff, who expressed distrust, labeled children who preferred technology to outdoor activities as lazy or did not have the skills to help with online tools (Williams-Peters, 2014). Denby et al. (2016) also reported that their smartphone intervention caused problems with trust between youth and caregivers and that foster parents felt the youths' use of phones usurped their authority. Rueda et al. (2019) also reported that staff had a widely discrepant perspective from youth about the value of technology; while youth were more nuanced about benefits and risks, staff perceptions were mostly negative. The technology was a source of disagreements, and staff used technology restriction as a form of punishment, which caused additional conflict between youth and staff involved in this research.

\section{Distraction}

Some youth admitted the distracting nature of online messages that interrupted either school or sleep. "Nick described that his mobile's audible push alerts, when one of his online friends posted, could awaken him at night, but he decided not to change the settings" (Sen, 2016, p. 1071). Sen (2016) also reported that interviews conducted with two former foster youth suggested potentially disruptive overuse of technology.

\section{Risk of Being Monitored}

Youth across studies discussed the risk and annoyance of being monitored by group home staff. For instance, youth in Williams-Peters' (2014) study described the use of technology experts brought in by their residential home who checked and monitored their computers for inappropriate settings and scheduled the hours they could use technology, which youth saw as disruptive to their autonomy. In Hammond et al. (2018), a 15-year-old participant described subverting the monitoring by using one sparse social media profile, and a second secret profile to reduce surveillance risks.

\section{Navigating Risks}

\section{Careful with Identity and Technology Settings}

Across studies, youth talked about the ways they took care with their identity. For instance, a youth in Sen's (2016) study reported, “... my foster parents are right like safety aware and they tell me not to put stuff like that on Facebook and plus it's got nothing to do with anybody where I am (p. 1068)." Sen reported that most participants in the study communicated primarily with people they knew to extend their relationships. Accounts from Hammond et al. (2018) participants are consistent with this judicious use of social media and use of social media settings to control access.

Youth also expressed an understanding of their digital footprints, for instance, from Sen (2016), “... say we were friends on Facebook-I could own a photo, tag you in the photo, yet you could then share it to someone that I don't want that photo to go to (p. 1068)." Hammond's participant shared, "they tried adding me and I just declined it (laughs) ... I don't exactly want them knowing my fucking business (p. 2069). Youth in other studies discussed the use of digital tools for safety, for instance, technology to limit views of their profile on social media, in Rueda et al. (2019), "that's why my block list is probably six pages long” (p. 532).

\section{Help-seeking}

In describing bullying behavior online, a young respondent in Sen's (2016) study responded that they talk to a teacher when this occurs. Another youth in Sen's study said, "I feel in control (of internet use) every time. If I ever had any problems I would just tell my foster mum (p. 1071).

\section{How Do Youth Describe the Relational Outcomes of Their ICT Use?}

\section{Finding and Maintaining Relationships with Family}

In multiple studies, youth shared that they used ICTs to find family members with whom they had lost contact due to placement in foster care. One foster care alumnus said, "... it allows you to connect to people from your past that you haven't spoken to in almost 10 years and they find you on Facebook...I've also been able to get in touch with my biological family from my grandma's side" (Roche et al., 2015, p. 5). In the study conducted by Denby et al. (2016), participants shared how ICT (smartphone) allowed them to stay in touch with family. One youth said, "We were like limited from talking on the house phone, and then when we came into DREAMR (the intervention study), we got our own phone, and we were able to talk to our families like hours" (p. 199). 


\section{Making and Sustaining Friendships and Romances}

Youth used technology to meet new people. In Rueda et al. (2019), technology was a central component of youth's romantic and sexual relationships. They used technology to meet, interact with, and sustain intimate partnerships. Youth also used technology to stay connected to their children's fathers. "I'll do whatever it takes to try again to be a family, like we supposed to" (Rueda et al., 2019, p. 13).

\section{Supporting Offline Relationships Online}

In several studies, youth utilized ICTs to stay connected to people in which they had already formed in-person relationships. "Almost all of my friends on Facebook are actually former foster youth or former probation youth, and I know them from organizations, from my time at these organizations" (Fowles, 2018, p. 50). This theme also appeared elsewhere, for instance, "I've been hanging around with him quite a lot recently with all his friends ... loads of people it's pretty smart... need to add Steve and them lot on Facebook really" (Hammond et al., 2018, p. 2066).

\section{Improved Relationships with and Access to Formal Support}

Youth used ICTs to connect with groups and learn of resources that can provide access to formal support. "A lot of the organizations that I'm part of here at [Big University] and outside of it have private groups. Sometimes, I find out a lot of information like events or volunteer opportunities or resources and scholarships on Facebook" (Fowles, 2018, p. 47). Similarly, youth used social media to maintain support with former group home staff. For instance, one youth described comfort in knowing that her group home had a social media profile which allower her to stay connected to staff during her transition out of care (Hammond et al., 2018).

\section{Discussion}

The most pressing question about ICT use that typically comes up for stakeholders concerned about the well-being of foster youth is the balance of risks to ICT access benefits. We reviewed research that included youth voice about their experience with ICTs as a way to support a youth voice lens. Our thematic analysis revealed that youth saw ICTs as facilitative to their positive relationships. Although it sometimes also caused stressors, in many instances, youth presented their strategies to manage them. However, youth could still benefit from supports in navigating ICTs to fill relational gaps. In fact, in some instances they spoke about the ways adults supported them in navigating issues such as online bullying. As with any normal but risky youth experience, such as driving, playing football, or going on a first date, youth benefit from preparation, coaching, guidance, and reflection from adults who care about them when they begin using ICTs.

Interestingly, the voice of youth about ICT use is mostly positive, counter to many narratives in popular child welfare discourse that focuses on harm associated with social media use. For instance, child welfare administrators (Stott et al., 2016), and foster parents and group home staff (Badillo-Urquiola et al., 2019, Badillo-Urquiola, Harpin, \& Wisniewski, 2017; Rueda et al., 2019) focus on harms to mental health and risky contacts on social media. Youth focus on relationships and the ability to control their narratives and make decisions about their own lives. The view of foster youth is supported by a growing body of longitudinal studies suggest no relationship between negative mental health outcomes and ICT use for adolescents (Orben \& Przybylski, 2019a, 2019b; Schemer, Masur, Geiß, Müller, \& Schäfer, 2020). Although additional research is needed related to ICT use by foster youth in particular, it is noteworthy that other marginalized youth, including homeless youth (Barman-Adhikari, Bowen, Bender, Brown, \& Rice, 2016; Rice \& Barman-Adhikari, 2014) and LGBTQ youth (McInroy, McCloskey, Craig, \& Eaton, 2019) are found to benefit relationally, and in other domains, from social media and other ICTs.

Here we map our discussion about the benefits of ICTs revealed in our analysis of the literature across Lerner's 5 "Cs," described as capacities, as a way to frame this discussion and help stakeholders consider potential positive interventions related to ICT use. The five "Cs" are competence, caring, connection, character, and confidence. Lerner and colleagues posit that the presence of the $5 \mathrm{cs}$ leads to a sixth $\mathrm{C}$, positive contributions to the community, and serves as a protective factor against problem behaviors. Although a number of formal interventions attempt to map their work to Lerner's 5 C's (Graham et al., 2015; Taussig et al., 2019; Travis \& Leech, 2014), we find that youth are able to meet many of these capacities informally via ICTs, which are likely both more accessible (when access is afforded) and acceptable to youth.

\section{Competence}

Competence in areas of social, vocational, and academic areas of life support youth in as they age out of foster care and enter the workforce and college (Geiger, Cheung, Hanrahan, Lietz, \& Carpenter, 2017). Our review of the literature revealed that technology use supports competencies related to normalized childhood experiences, development of digital skills, and resource finding pertaining 
to education and vocational skills. Social competence, which supports resilience and protects against depression (Askeland et al., 2020), includes problem-solving in relationships and positive decision making. Youth participants in studies we reviewed reported that ICTs allowed them to navigate complicated relationships and make decisions about managing their public identities online. A PYD lens posits that these growth opportunities are valuable, even when they are risky.

\section{Confidence}

Confidence refers to the individual's view of their global capacities. Foster youth have reported poor confidence regarding their own decision-making as they leave foster care (Geiger et al., 2017). Ahrens et al. (2011) note the that relationships for foster youth are important in helping them learn about how to confidently set relational boundaries and problem-solve in relationships. In studies we reviewed, youth who used technology said they built confidence regarding their ability to make good decisions in managing who they let into their virtual lives. They were even sometimes in situations where they were confident that their technology skills exceeded those of their caregivers, offering an opportunity to flip the script of typical experiences in which others have authority over youth. This is noteworthy given that youth in care often see themselves as powerless to adults in the system (King, Abrego, Narendorf, Ha, \& Maria, 2017).

\section{Connection}

Connection here refers to the positive experience youth have with the broader environment, including programs and individuals. Notably, studies in this literature review highlighted that foster youth's primary social experiences are often institutionalized, i.e., youth communicate primarily with other foster youth or formal providers who are known to them due to their care status. However, youth are more likely to turn to informal supports and peers when they need help (Ruff \& Harrison, 2019). ICTs provide instances for youth to communicate with others who are not part of the child welfare system, and even allows them to control and hide their identities as foster youth if they choose. Additionally, youth connect with family members, deepen new face-to-face relationships, and find new friends in a setting where they can control their self-disclosure. Relational connections reduce many risks to youth as the age out of care (Blakeslee \& Best, 2019). Self-disclosure via ICTs appears to strengthen online and in-person relationships (Desjarlais, 2020). Online friendships are shown to have significant benefits for marginalized youth, such as LGBTQ youth (McInroy, 2019; McInroy et al., 2019). There is little argument that the child welfare system does a poor job of facilitating connections for foster youth, and it seems evident that in our current digital culture technology can facilitate connection.

\section{Character}

Character represents morality, the expression of values, and respect for regulations. Parents, and then after-school programs and peers, are thought to be primary sources of character development (Lerner, 2018); however, foster youth are often deprived of these opportunities. According to youth in the studies reviewed, they practiced character development informally in the navigation of interpersonal relationships, such as with whom they wanted to maintain online relationships, and in working to positive self-representation in online settings. It is worth noting that several researchers who authored studies in our review of literature also challenged the moral messages about youth's character that were sometimes assumed by caregivers related to their ICT use. For instance, caregivers suggested that technology use symbolized poor decision-making or laziness, countering the youths' experiences with values-based decision-making. To embrace youth voice in decision making also means watching for adult biases about ICTs.

\section{Caring/Compassion}

Caring and compassion refer to the capacity to be sympathetic and empathetic. This skill relies on interpersonal experiences. Again, foster youth often lack opportunities for interpersonal social supports (Best \& Blakeslee, 2020; Blakeslee \& Best, 2019). Youth participants across studies reported that they developed relational skills through the use of ICTs that provided insights into others' experiences and allowed them to reflect more deeply on their own experiences. This fits with existing longitudinal research that suggests ICTs improve empathy skills in adolescents (Vossen \& Valkenburg, 2016).

\section{Contribution}

Lerner et al. (2015) suggest that capacities across the five Cs support a sixth C, contribution. Their research supports that youth with capacities discussed here can make valuable contributions to society, and these capacities, when present in youth, are negatively correlated with problem behaviors. Although the theme did not emerge in our research, this may be because foster youth in the study were seldom supported in developing digital literacy skills to the degree in which they could make contributions. On the other hand, youth across the globe currently demonstrate contributions to digital communities, build fundraising campaigns, and even start 
social movements online, which benefit self-esteem, mental health, and belonging (Cho et al., 2020).

\section{Implications}

\section{Practice Implications}

Youth in the studies we reviewed described relational tension that occurs via social media, including the pressure and judgment of caregivers related to their ICT use. Given this dynamic, foster youth may be reluctant to turn to caregivers for problem-solving regarding technology, even though the existing research suggests that parental mediation and healthy relationships may reduce online risks for adolescents (Livingstone et al., 2017; Wisniewski et al., 2015). A logical response to these problems includes healthy online relationship education for youth, as well as realistic media mediation education for caregivers, and agency policies that support these outcomes. Social work educators can help prepare emerging practitioners with ICT literacy, including balanced views of the risks and benefits of ICTs, centering human relationships. Other stakeholders in practice settings, including supervisors, caseworkers, therapists, and foster parents, may also benefit from continuing education about how to support foster youths' healthy use of technology.

The PYD framework offers considerations for specific areas of interventions for youth related to their ICT use. For instance, interventions might focus on areas of relational competency in online environments, which may strengthen youth competency in both online and offline spaces, improving youth opportunities to make positive contributions in society, as posited by Lerner's (2015) PYD model.

\section{Policy Implications}

Child welfare agencies generally do not have policies that govern the routine use of ICTs for foster youth (Sage \& Sage, 2016). Caseworkers and foster parents fill this void by making decisions guided by their own values, which is often counter to child welfare scholars' advice, as they generally suggest that ICTs support relationships and identity normal adolescent exploration (Graham et al., 2015; Gustavsson \& MacEachron, 2015; Sen, 2016). For instance, many foster parents make fear-based decisions about ICT use by adolescents in their care (Badillo-Urquiola et al., 2019; Wisniewski et al., 2015). Others may not know enough about ICTs to make "prudent" decisions (Pokempner et al., 2015) required by federal child welfare law (Alford, Denby, \& Gomez, 2019). These facts call for stronger research-based policies in child welfare settings that outline youth rights related to ICTs. One model policy is the Los Angeles County Foster Youth Bill of Rights (2020), which states that children in foster care have the right to private use of email and internet unless restricted by a judge, and only revocable in the face of specific risks.

\section{Future Research}

Our review focused on youth experiences of those who had access to ICTs. Still, little research exists about the degree to which foster youth generally have access to social media or ICTs more broadly. A 2004 paper and intervention study that sought to reduce the digital divide for foster youth and families reported on a Casey Families needs-assessment, which found that only a third of foster youth used the internet, and one in ten used email (Finn, Kerman, \& LeCornec, 2004). Although access is likely improved today, the scant existing research points to restriction of access to technology for foster youth (Badillo-Urquiola et al., 2017, 2019). We are aware of several situations in which federal, national, and local partners recently scurried to meet the needs for technology access for youth so they could attend school from a distance during the COVID-19 pandemic (American Bar Association, 2020; Milner, 2020; Think of Us, 2020). This suggests existing access and service gaps. Given this recent international pandemic and its effect on youth access to supportive others, it is more important than ever that additional research explores foster youth experiences with technology and how to navigate it in healthy ways.

Additionally, although youth had nuanced perspectives of their ICT use and reported benefits of technology alongside risks in the research we reviewed, few models exist for supporting youth through positive and healthy navigation of ICTs. More research is necessary related to how to enact these types of interventions and support online civic engagement so that foster youth can fully appreciate opportunities available online.

\section{Limitations}

This review has limitations that should be acknowledged. First, this review did not include a thorough search of gray literature. We realize that child welfare workers, foster parents, and others intimately involved in the child welfare system know of first-hand incidents in which youth benefitted or experienced risks related to ICTs, and that these often do not make it to the published literature because of gaps in practice-informed evidence (Wesley et al., 2020). Second, although the authors followed best practices in developing a search strategy, it is possible that the search terms used did not exhaust the available literature. Finally, this review focused on youth perspectives and youth voice. Other studies that focus on adult perceptions of ICT use offer differing views on the benefits and risks of youth access to ICTs and tend to focus on risks associated with social media access. However, given the clear need for youth to be more involved 
in decision-making about their lives, we believe this youthcentered perspective is an essential addition to the literature.

\section{Conclusion}

Models of youth development often focus on deficits and risk factors associated with adolescence, and this may be even more true for youth in foster care who experience increased status-related vulnerabilities. A deficit perspective naturally leads to case management interventions that correct problem behaviors or the adverse effects of these vulnerabilities, e.g., treating anxiety and depression, or trying to control access to potentially risky behavior. Resilience theory (Masten, 2007; Wright \& Masten, 2015) encourages interventions that boost protective factors as another way to reduce adverse outcomes for youth. A Positive Youth Development framework can help identify protective capacities that support PYD and how ICT use may facilitate protective factors. Youth need support in access and reflection to make the most of ICTs.

There is little indication that technology use is waning. In the United States of America, stakeholders like to imagine the basic needs of foster youth are met and that we are a progressive country when it comes to preparing youth for the digital future. We might learn lessons from unexpected regions, including the Caribbean, where the Ministry of Education gives all youth who reach secondary school a laptop to help them develop ICT competencies so they can compete in a globalized world (Williams-Peters, 2014). In the United Kingdom, the Government Council for Internet Safety has produced publications for parents, educators, policymakers, and internet providers, including the digital skills youth should possess and the broader community's responsibilities to assure child safety and rights online (UKCIS Working Group, 2020). They suggest a resilience lens, encouraging youth to engage in opportunities online, and to practice use active coping rather than avoidance in order to promote growth and self-determination in digital spaces.

In 2019, the Federal Children's Bureau brought together national experts to discuss ways to support youth in foster care, and their summary report highlighted normative developmental experiences of youth, including the importance of peers, gradual independence, opportunities for taking risks, identity development, and understanding and communicating emotions (McKenzie, 2020). To promote normal development for foster youth, and follow the federal Strengthening Families Act of 2014 (P.L. 113-183) that dictates child welfare agencies and foster parents facilitate normative experiences for foster youth, our child welfare stakeholders must respond to the challenge of ICT access and use. This systematic review suggests that, despite risks,
ICTs hold value as a protective tool for promoting Positive Youth Development. It is perhaps an especially beneficial tool to meet the relational and normal developmental needs of youth in foster care.

\section{References}

Ahrens, K. R., DuBois, D. L., Garrison, M., Spencer, R., Richardson, L. P., \& Lozano, P. (2011). Qualitative exploration of relationships with important non-parental adults in the lives of youth in foster care. Children and Youth Services Review, 33(6), 1012-1023.

Alford, K. A., Denby, R. W., \& Gomez, E. (2019). Use of smartphone technology in foster care to build relational competence: Voices of caregivers and implications for prudent parenting. Journal of Family Social Work, 22(3), 209-230. https://doi.org/10.1080/10522 158.2018.1558428.

American Bar Association. (2020, March 20). At-home education and learning resources for foster youth during COVID19. Retrieved from https://www.americanbar.org/groups/litigation/committees /childrens-rights/practice/2020/at-home-education-and-learningresources-for-foster-youth-during-covid-19/.

Anderson, M., \& Jingjing, J. (2018, May 31). Teens, social media \& technology 2018. Pew Research Center: Internet, Science \& Tech. Retrieved from https://www.pewresearch.org/internet/2018/05/31/ teens-social-media-technology-2018/.

Armstrong-Heimsoth, A., Hahn-Floyd, M., Williamson, H. J., Kurka, J. M., Yoo, W., \& Rodríguez De Jesús, S. A. (2020). Former foster system youth: Perspectives on transitional supports and programs. The Journal of Behavioral Health Services \& Research. https:// doi.org/10.1007/s11414-020-09693-6.

Askeland, K. G., Bøe, T., Breivik, K., Greca, A. M. L., Sivertsen, B., \& Hysing, M. (2020). Life events and adolescent depressive symptoms: Protective factors associated with resilience. PLOS ONE, 15(6), e0234109.

Badillo-Urquiola, K., Harpin, S., \& Wisniewski, P. (2017). Abandoned but not forgotten: Providing access while protecting foster youth from online risks. In: Proceedings of the 2017 Conference on Interaction Design and Children, (pp. 17-26). https://doi. org/10.1145/3078072.3079724

Badillo-Urquiola, K., Page, X., \& Wisniewski, P. J. (2019). Risk vs. restriction: The tension between providing a sense of normalcy and keeping foster teens safe online. In: Proceedings of the 2019 CHI Conference on Human Factors in Computing Systems, (pp. $1-14)$.

Barman-Adhikari, A., Bowen, E., Bender, K., Brown, S., \& Rice, E. (2016). A social capital approach to identifying correlates of perceived social support among homeless youth. Child \& Youth Care Forum, 45(5), 691-708. https://doi.org/10.1007/s1056 6-016-9352-3.

Baumeister, R. F., \& Leary, M. R. (1997). Writing narrative literature reviews. Review of General Psychology, 1(3), 311-320.

Beal, S. J., Wingrove, T., Nause, K., Lipstein, E., Mathieu, S., \& Greiner, M. V. (2019). The role of shared decision-making in shaping intent to access services for adolescents in protective custody. Child Care in Practice, 25(1), 64-78. https://doi. org/10.1080/13575279.2018.1521379.

Benbenishty, R., Davidson-Arad, B., López, M., Devaney, J., Spratt, T., Koopmans, C., ... Hayes, D. (2015). Decision making in child protection: An international comparative study on maltreatment substantiation, risk assessment and interventions recommendations, 
and the role of professionals' child welfare attitudes. Child Abuse \& Neglect, 49, 63-75.

Best, J. I., \& Blakeslee, J. E. (2020). Perspectives of youth aging out of foster care on relationship strength and closeness in their support networks. Children and Youth Services Review, 108, 104626.

Blakeslee, J. E. (2015). Measuring the support networks of transitionage foster youth: Preliminary validation of a social network assessment for research and practice. Children and Youth Services Review, 52, 123-134. https://doi.org/10.1016/j.childyouth .2015.03.014.

Blakeslee, J. E., \& Best, J. I. (2019). Understanding support network capacity during the transition from foster care: Youth-identified barriers, facilitators, and enhancement strategies. Children and Youth Services Review, 96, 220-230. https://doi.org/10.1016/j. childyouth.2018.11.049.

Braun, V., \& Clarke, V. (2014). What can "thematic analysis" offer health and well-being researchers? International Journal of Qualitative Studies on Health and Well-Being. https://doi.org/10.3402/ qhw.v9.26152.

Annie E Casey Foundation. (2014, November 14). Indicator Selection I KIDS COUNT Data Center. Retrieved from http://datacenter.kidsc ount.org/data/share/ND 2 0\#ND/2/0.

Children's Bureau. (2020). AFCARS Report \#27 (Preliminary FY 2019 Estimates of Child Welfare Outcomes No. 27; The AFCARS Report). U.S. Department of Health and Human Services. Retrieved from https://www.acf.hhs.gov/cb/resource/afcars-repor t-27.

Christensson, P. (2010, January 4). ICT (Information and Communication Technologies) Definition. Retrieved from https://techterms. com/definition/ict.

Denby, R. W., Gomez, E., \& Alford, K. A. (2016). Promoting wellbeing through relationship building: The role of smartphone technology in foster care. Journal of Technology in Human Services, 34(2), 183-208

Desjarlais, M. (2020). Online self-disclosure: Opportunities for enriching existing friendships. The Psychology and Dynamics Behind Social Media Interactions. https://doi.org/10.4018/978-1-52259412-3.ch001.

Eichas, K., Ferrer-Wreder, L., \& Olsson, T. M. (2019). Contributions of positive youth development to intervention science. Child \& Youth Care Forum. https://doi.org/10.1007/s10566-018-09486-1.

Espinoza, G., \& Wright, M. (2018). Cyberbullying experiences among marginalized youth: What do we know and where do we go next? Journal of Child \& Adolescent Trauma, 11(1), 1-5.

Fawley-King, K., Trask, E. V., Zhang, J., \& Aarons, G. A. (2017). The impact of changing neighborhoods, switching schools, and experiencing relationship disruption on children's adjustment to a new placement in foster care. Child Abuse \& Neglect, 63, 141-150. https://doi.org/10.1016/j.chiabu.2016.11.016.

Fergus, S., \& Zimmerman, M. A. (2005). Adolescent resilience: A framework for understanding healthy development in the face of risk. Annual Review of Public Health, 26, 399-419.

Finn, J., Kerman, B., \& LeCornec, J. (2004). Building skillsbuilding futures: Providing information technology to foster families. Families in Society, 85(2), 165-176. https://doi. org/10.1606/1044-3894.317.

Forenza, B., Bermea, A., \& Rogers, B. (2018). Ideals and reality: Perceptions of healthy and unhealthy relationships among foster youth. Child and Adolescent Social Work Journal, 35(3), 221230. https://doi.org/10.1007/s10560-017-0523-3.

Foster Club. (2016). Permanency pact: Life-long, kin-like connections between a youth and a supportive adult. http://www.fosterclub .com.

Fowles, T. M. (2018). Fosteredtech: Exploring how foster care alumni use social media [PhD Thesis]. University of Southern California.
Geiger, J. M., Cheung, J. R., Hanrahan, J. E., Lietz, C. A., \& Carpenter, B. M. (2017). Increasing competency, self-confidence, and connectedness among foster care alumni entering a 4-year university: Findings from an early-start program. Journal of Social Service Research, 43(5), 566-579.

Goodkind, S., Schelbe, L. A., \& Shook, J. J. (2011). Why youth leave care: Understandings of adulthood and transition successes and challenges among youth aging out of child welfare. Children and Youth Services Review, 33(6), 1039-1048. https://doi. org/10.1016/j.childyouth.2011.01.010.

Graham, K. E., Schellinger, A. R., \& Vaughn, L. M. (2015). Developing strategies for positive change: Transitioning foster youth to adulthood. Children and Youth Services Review, 54, 71-79. https ://doi.org/10.1016/j.childyouth.2015.04.014.

Gustavsson, N., \& MacEachron, A. (2015). Positive Youth Development and foster care youth: A digital perspective. Journal of Human Behavior in the Social Environment, 25(5), 407-415.

Hammond, S. P., Cooper, N., \& Jordan, P. (2018). Social media, social capital and adolescents living in state care: A multi-perspective and multi-method qualitative study. The British Journal of Social Work, 48(7), 2058-2076.

Havlicek, J. (2011). Lives in motion: A review of former foster youth in the context of their experiences in the child welfare system. Children and Youth Services Review, 33(7), 1090-1100. https:// doi.org/10.1016/j.childyouth.2011.02.007.

Hinduja, S., \& Patchin, J. W. (2017). Cultivating youth resilience to prevent bullying and cyberbullying victimization. Child Abuse \& Neglect, 73, 51-62.

King, B., Abrego, D., Narendorf, S., Ha, Y., \& Maria, D. S. (2017). Representations of homelessness, home environments, and authority in the context of runaway behaviors reported by foster care youth residing in an emergency shelter. Journal of Social Distress and Homelessness, 26(2), 138-147.

Lerner, R. M. (2018). Character development among youth: Linking lives in time and place. International Journal of Behavioral Development, 42(2), 267-277.

Lerner, R. M., Lerner, J. V., Bowers, E., \& JohnGeldhof, G. (2015). Positive youth development and relational-developmental-systems. In R. M. Lerner (Ed.), Handbook of child psychology and developmental science (pp. 1-45). Hoboken: Wiley.

Leung, L. (2014). Predicting Internet risks: A longitudinal panel study of gratifications-sought, Internet addiction symptoms, and social media use among children and adolescents. Health Psychology and Behavioral Medicine, 2(1), 424-439. https://doi. org/10.1080/21642850.2014.902316.

Lindell, K. U., Sorenson, C. K., \& Mangold, S. V. (2020). The Family First Prevention Services Act: A new era of child welfare reform. Public Health Reports, 135(2), 282-286.

Livingstone, S., Ólafsson, K., Helsper, E. J., Lupiáñez-Villanueva, F., Veltri, G. A., \& Folkvord, F. (2017). Maximizing opportunities and minimizing risks for children online: The role of digital skills in emerging strategies of parental mediation. Journal of Communication, 67(1), 82-105.

Los Angeles County Foster Youth Bill of Rights. (2020). Retrieved from https://layouthrights.com/foster-youth-rights/.

Lundy, C. (2011). Social work, social justice \& human rights: A structural approach to practice. Toronto: University of Toronto Press.

Masten, A. S. (2007). Resilience in developing systems: Progress and promise as the fourth wave rises. Development and Psychopathology, 19(3), 921-930. https://doi.org/10.1017/S09545794070004 42.

McInroy, L. B. (2019). Building connections and slaying basilisks: Fostering support, resilience, and positive adjustment for sexual and gender minority youth in online fandom communities. Information, Communication \& Society. https://doi.org/10.1080/13691 18X.2019.1623902. 
McInroy, L. B., McCloskey, R. J., Craig, S. L., \& Eaton, A. D. (2019). LGBTQ+ youths' community engagement and resource seeking online versus offline. Journal of Technology in Human Services, 37(4), 315-333. https://doi.org/10.1080/15228835.2019.1617823.

McKenzie, K. (2020). Building capacity in foster care to support the self-regulation development of youth and young adults: Meeting summary (No. 2020-56; p. 8). Office of Planning, Research, and Evaluation, Administration for Children and Families, U.S. Department of Health and Human Services.

McLaughlin, A. M., Gray, E., \& Wilson, M. (2015). Child welfare workers and social justice: Mending the disconnect. Children and Youth Services Review, 59, 177-183. https://doi.org/10.1016/j. childyouth.2015.11.006.

Milner, J. (2020, April 17). The availability of federal funding and other resources to assist with the purchase of cell phones and plans to facilitate and maintain contact. Retrieved from https ://www.cwla.org/wp-content/uploads/2020/04/Childrens-Burea u-Letter-on-Federal-Funds-Use-for-Cell-Phones-and-PPE.pdf.

Mitchell, M. B. (2018). "No one acknowledged my loss and hurt": Nondeath loss, grief, and trauma in foster care. Child and Adolescent Social Work Journal, 35(1), 1-9. https://doi.org/10.1007/s1056 0-017-0502-8.

Mitchell, M. B., Jones, T., \& Renema, S. (2015). Will I make it on my own? Voices and visions of 17-year-old youth in transition. Child and Adolescent Social Work Journal, 32(3), 291-300.

Moher, D., Liberati, A., Tetzlaff, J., \& Altman, D. G. (2009). Preferred reporting items for systematic reviews and meta-analyses: The PRISMA statement. PLoS Med, 6(7), e1000097.

Munson, M. R., Smalling, S. E., Spencer, R., Scott, L. D., \& Tracy, E. M. (2010). A steady presence in the midst of change: Non-kin natural mentors in the lives of older youth exiting foster care. Children and Youth Services Review, 32(4), 527-535. https://doi. org/10.1016/j.childyouth.2009.11.005.

Murad, M. H., Asi, N., Alsawas, M., \& Alahdab, F. (2016). New evidence pyramid. EBMJ Evidence-Based Medicine, 21(4), 125-127.

Nybell, L. M. (2013). Locating "youth voice:" Considering the contexts of speaking in foster care. Children and Youth Services Review, 35(8), 1227-1235.

Olson, A., Scherer, D. G., \& Cohen, A. L. (2017). Decision-making skills of emerging adults aging out of foster care. Children and Youth Services Review, 82, 81-86. https://doi.org/10.1016/j.child youth.2017.09.023.

Orben, A., \& Przybylski, A. K. (2019a). The association between adolescent well-being and digital technology use. Nature Human Behaviour, 3(2), 173-182.

Orben, A., \& Przybylski, A. K. (2019b). Screens, teens, and psychological well-being: Evidence from three time-use-diary studies. Psychological Science, 30(5), 682-696.

Pokempner, J., Mordecai, K., Rosado, L., \& Subrahmanyam, D. (2015). Promoting normalcy for children and youth in foster care. 31.

Pryce, J., Napolitano, L., \& Samuels, G. M. (2017). Transition to adulthood of former foster youth: Multilevel challenges to the helpseeking process. Emerging Adulthood, 5(5), 311-321. https://doi. org/10.1177/2167696816685231.

Rice, E., \& Barman-Adhikari, A. (2014). Internet and social media use as a resource among homeless youth. Journal of ComputerMediated Communication, 19(2), 232-247.

Roche, C., Vaterlaus, J. M., \& Young, J. A. (2015). A foster care alumna's past and present technological experience: A feminist case study approach. Sage Open, 5(2), 2158244015584946.

Rogers, J. (2016). Preserving relationships and maintaining social capital: The experiences of young people living in foster care in the United Kingdom. Youth Divide and Youth Inclusion: Agendas and Alternative

Rueda, H. A., Brown, M. L., \& Geiger, J. M. (2019). Technology and dating among pregnant and parenting youth in residential foster care: A mixed qualitative approach comparing staff and adolescent perspectives. Journal of Adolescent Research. https://doi. org/10.1177/0743558419861087.

Ruff, S. C., \& Harrison, K. (2019). "Ask me what I want": Community-based participatory research to explore transition-age foster youth's use of support services. Children and Youth Services Review. https://doi.org/10.1016/j.childyouth.2019.104608.

Sage, M., \& Sage, T. (2016). Social media and e-professionalism in child welfare: Policy and practice. Journal of Public Child Welfare, 10(1), 79-95. https://doi.org/10.1080/15548732.2015.10995 89.

Salazar, A. M., Keller, T. E., \& Courtney, M. E. (2011). Understanding social support's role in the relationship between maltreatment and depression in youth with foster care experience. Child Maltreatment, 16(2), 102-113.

Schemer, C., Masur, P. K., Geiß, S., Müller, P., \& Schäfer, S. (2020). The impact of internet and social media use on well-being: A longitudinal analysis of adolescents across nine years. Journal of Computer-Mediated Communication. https://doi.org/10.1093/ jcmc/zmaa014.

Seita, J., Day, A., Carrellas, A., \& Pugh, G. L. (2016). Assessing the help-seeking behaviors of foster care alumni within their own social networks. Journal of Sociology and Social Work. https:// doi.org/10.15640/jssw.v4n2a1.

Sen, R. (2016). Not all that is solid melts into air? Care-experienced young people, friendship and relationships in the 'digital age.' The British Journal of Social Work, 46(4), 1059-1075.

Simmons-Horton, S. Y. (2017). Providing age-appropriate activities for youth in foster care: Policy implementation process in three states. Children and Youth Services Review, 82, 383-391. https:// doi.org/10.1016/j.childyouth.2017.10.007.

Simpson, J. E. (2016). A divergence of opinion: How those involved in child and family social work are responding to the challenges of the Internet and social media. Child \& Family Social Work, 21(1), 94-102. https://doi.org/10.1111/cfs.12114.

Smith, J. A. (2015). Qualitative psychology: A practical guide to research methods. London: SAGE.

Storer, H. L., Barkan, S. E., Stenhouse, L. L., Eichenlaub, C., Mallillin, A., \& Haggerty, K. P. (2014). In search of connection: The foster youth and caregiver relationship. Children and Youth Services Review, 42, 110-117. https://doi.org/10.1016/j.childyouth .2014.04.008.

Stott, T. C., MacEachron, A., \& Gustavsson, N. (2016). Social media and child welfare: Policy, training, and the risks and benefits from the administrator's perspective. Advances in Social Work, 17(2), 221-234. https://doi.org/10.18060/21263.

Taussig, H. N., Weiler, L. M., Garrido, E. F., Rhodes, T., Boat, A., \& Fadell, M. (2019). A positive youth development approach to improving mental health outcomes for maltreated children in foster care: Replication and extension of an RCT of the Fostering Healthy Futures Program. American Journal of Community Psychology, 64(3-4), 405-417.

Taylor, R. D., Oberle, E., Durlak, J. A., \& Weissberg, R. P. (2017). Promoting positive youth development through school-based social and emotional learning interventions: A meta-analysis of follow-up effects. Child Development, 88(4), 1156-1171. https:// doi.org/10.1111/cdev.12864.

Think of Us. (2020, March 19). COVID-19 Town Hall. Virtual Town Hall for Older Foster Youth. https://www.thinkof-us.org/ town-hall-1

Thompson, H. M., Wojciak, A. S., \& Cooley, M. E. (2016). Selfesteem: A mediator between peer relationships and behaviors of adolescents in foster care. Children and Youth Services Review, 66, 109-116. https://doi.org/10.1016/j.childyouth.2016.05.003.

Travis, R., \& Leech, T. G. J. (2014). Empowerment-based positive youth development: A new understanding of healthy development 
for African American youth. Journal of Research on Adolescence (Wiley-Blackwell), 24(1), 93-116

UKCIS Working Group. (2020, December 14). UK Council for Child Internet Safety (UKCCIS) [Government]. UK Council for Child Internet Safety. Retrieved from https://www.gov.uk/government/ groups/uk-council-for-child-internet-safety-ukccis.

Vossen, H. G. M., \& Valkenburg, P. M. (2016). Do social media foster or curtail adolescents' empathy? A longitudinal study. Computers in Human Behavior, 63, 118-124. https://doi.org/10.1016/j. chb.2016.05.040.

Wesley, B. C., Pryce, J., \& Samuels, G. M. (2020). Meaning and essence of child well-being according to child welfare professionals. Child and Adolescent Social Work Journal, 37(4), 425-441. https://doi.org/10.1007/s10560-019-00638-3.

Williams-Peters, K. (2014). The online and offline realities of children in residential care in trinidad. Social and Economic Studies, 177-206.

Wilson, S. (2016). Digital technologies, children and young people's relationships and self-care. Children's Geographies, 14(3), 282-294.
Wisniewski, P., Jia, H., Xu, H., Rosson, M. B., \& Carroll, J. M. (2015). "Preventative" vs." reactive" how parental mediation influences teens' social media privacy behaviors. Proceedings of the 18th ACM Conference on Computer Supported Cooperative Work \& Social Computing, (pp. 302-316).

Wright, M. O., \& Masten, A. S. (2015). Pathways to resilience in context. In L. Theron, L. Leibenberg, \& M. Ungar (Eds.), Youth resilience and culture: Commonalities and complexities (pp. 3-22). New York: Springer.

Publisher's Note Springer Nature remains neutral with regard to jurisdictional claims in published maps and institutional affiliations. 